\title{
RESPONSE OF RICE (ORYZA SATIVA L.) UNDER ELEVATED TEMPERATURE AT EARLY GROWTH STAGE: PHYSIOLOGICAL MARKERS
}

\author{
Muhammad Kazim Ali, Abid Azhar, Saddia Galani, Researchers \\ Karachi Institute of Biotechnology and Genetic Engineering (KIBGE), \\ University of Karachi, Karachi, Pakistan \\ E-mail: ali.kazimm@gmail.com
}

\begin{abstract}
A reliable and rapid assessment technique, for evaluation of cultivars having potential to combat harsh environmental conditions is imperative. This experiment was carried out to screen 8 local (Pakistan) accessions of rice at early growth stage (germination and seedling) at control $\left(28 \pm 3^{\circ} \mathrm{C}\right)$ and heat shock $\left(42 \pm 3^{\circ} \mathrm{C}\right)$ for different time periods $(24,48,72 \mathrm{~h})$. Heat stress indices, including promptness index (P.I.) and germination stress index (G.S.I.), were used to explore thermotolerance at germination stage. At seedling stage, relative membrane permeability (RMP) were assessed through measurement of electrolyte leakage (EC), melondialdehyde (MDA) and production of hydrogen peroxide $\left(\mathrm{H}_{2} \mathrm{O}_{2}\right)$. It is observed that heat stress delayed germination and decreased germination percentage at germination stage. However cultivars showed significantly different response. Among all, "Kanwal-95" showed more thermotolerance in terms of maximum number of germination as well as in speediness to germination. Physiological indicators manifested, increased electrolyte leakage is associated with increased level of lipid peroxidation and hydrogen peroxide. It can be concluded that antioxidants enzymes could play major role in thermotolerance by scavenging free radicals to protect lipid peroxidation consequently improve cell membrane thermostability. Results analysis revealed that these indicators were simple and accurate selection criteria to assess heat stress effect and can be adopted to save resources and time of formers.
\end{abstract}

\section{KEY WORDS}

Heat stress; Germination percentage; Electrolyte leakage; Lipid peroxidation; Free radical.

Rice (Oryza sativa L.) is one of the most important food crop among cereals (Eckardt, 2009). It is consumed by $90 \%$ in tropical Asia (Parasad et al., 2006), and is being used as staple food by world's half population (Muhammad et al., 2009). Rice current production rate should increase approximately by $1 \%$ per year not only for the world's growing population food demands (Sass et al. 2002) but also due to adverse climatic conditions. Human development and some natural factors (Eitzinger et al., 2010), projected to uplift surface air temperature $2-4{ }^{\circ} \mathrm{C}$ by the end of $21^{\text {st }}$ Century (IPCC, 2007). According to a study conducted at International Rice Research Institute, Manila, Philippines, annual mean maximum and minimum temperature have increased by $0.35^{\circ} \mathrm{C}$ and $1.13^{\circ} \mathrm{C}$ for the period of 1979-2003, respectively (Peng et al., 2004). For each $1^{\circ} \mathrm{C}$ increase in temperature during crop growing period, grain yield of rice declined by $10 \%$ (Peng et al., 2004), developing 40$50 \%$ gape between attainable and the actual yield (Vanderauwera et al., 2007). Due to sharp decline in cultivable land avaiability, unsufficient supply of water and continous increase in food demand (Eldakak et al., 2013), farmers are forced to cultivate the rice in marginal environment with warmer temperature (Prasad et al., 2006) which ultimately leads to the crop vulnerability along with reduced yield (Nakagawa et al., 2003).

Certain abiotic stresses including extreme temperature have detrimental effect on plant growth and crop yield. Among all changing climatic factors, mainly increasing average temperature is well known factor causing reduction in growth and productivity (Southworth et al., 2000). Long exposure of high temperature during seed development triggers delaying in germination, seed vigor (Grass et al., 1995) and dry mass reduction (Wahid et al., 2007). While seed germination and seedling establishment stage play vital role for sustainable cropping, and are more sensitive to high temperatures (Spiertz et al., 2006; Dias et al., 2011) assessing varying degree of stress tolerance at different developmental stages. Such inter- 
specific and intra-specific variations at different growth stages (Takeda et al., 1995; Ashraf et al., 2004) may improve early germination and faster field emergence to cope with adverse germination conditions (McDonald et al., 2000).

Among the major impacts of heat stress is induction of oxidative stress (Wahid et al., 2007). First event of stress conditions is the generation of reactive oxygen species (ROS) i.e. hydrogen peroxide, hydroxyl radicals and singlet oxygen (Noctor and Foyer, 1998). These are highly reactive as the can interact with number of cellular molecules and essential plant metabolites hereby leading to destructive processes causing cell death (Ashraf, 2009). Reactive oxygen species causes the autocatalytic per oxidation of membrane lipids and pigments leading to loss of membrane semi permeability and modifying its function (Xu et al., 2006).

Due to complexity of heat stress, there is need to develop quick and fast screening tests for heat tolerance and plant breeders are still in quest for identifying such efficient screening tools for detecting heat tolerance potentials at early growth stages in crop plants. In this regard, there is entire dearth of information regarding potentials of germination ability difference and cell membrane thermostability among rice cultivars with respect to genotype screening of heat tolerance under heat stress. Keeping in view these facts, this experiment was carried out using eight cultivars of rice Sindh Pakistan to determine response of high temperature at germination and seedling stages.

\section{MATERIALS AND METHODS}

This experiment was conducted at Agricultural Biotechnology Division, Karachi Institute of Biotechnology and Genetic Engineering (KIBGE) University of Karachi Pakistan. Rice cultivars were collected from Rice Research Institute, Dokri, Sindh Pakistan (Table 1).

Table 1 - Rice cultivars used in the study

\begin{tabular}{|c|c|c|c|}
\hline S no & Genotype & 100 grains weight $(\mathrm{g})$ & Seed Size \\
\hline 1 & IR-6 & 1.40 & Small \\
\hline 2 & IR-8 & 1.45 & Large \\
3 & DR-82 & 1.08 & Medium \\
4 & DR-83 & 0.97 & Small \\
5 & DR-92 & 1.20 & Small \\
6 & Kawal 95 & 1.12 & Large \\
7 & Sada Hayat & 1.23 & Medium \\
8 & Shahkar & 1.18 & Medium
\end{tabular}

Fresh seeds were washed with distilled water and treated with $70 \%$ ethanol for 20 second followed by sterilizing with $10 \%$ Sodium Hypochlorite (commercial bleach) for 30 minutes. Seeds were rinsed five times with autoclaved distilled water and then soaked in water for $24 \mathrm{hrs}$. Seeds were divided into two groups one for germination at normal $\left(28 \pm 3^{\circ} \mathrm{C}\right)$ and one at high temperature $\left(42 \pm 3^{\circ} \mathrm{C}\right)$. Later, seeds kept at high temperature for $24 \mathrm{hrs}, 48$ hrs and 72 hrs. Both control and stressed seeds allowed to germination in Petri plates with filter paper wetted with distilled water at $28 \pm 3^{\circ} \mathrm{C}$ in controlled growth chamber. When the radical emerged through the seed coat it was considered as germinated. From the start of the test, data were documented for two weeks. Data collected after every second day. Then, Promptness index (P.I), germination stress index (GSI) were calculated according to Bouslama and Schapaugh, 1984.

i. P.I $=n d_{2}(1.0)+n d_{4}(0.75)+n d_{6}(0.50)+n d_{8}(0.25) n$ number of seeds germinated at day d. In which nd2, nd4, nd6, nd8, and nd10 represent the percentage of germinated seeds after 2, 4, 6, 8 and 10 days after sowing, respectively.

ii. G.S.I. $(\%)=[$ P.I of stressed seeds / P.I of control seeds] $\times 100$.

Seedling estalishment and Stress treatment. Seeds were primed in water for 2 days. Seedling allowed to grow in natural sunlight with 700 flux light intensity, daily mean temperature was $28^{\circ} \mathrm{C}$. After 20 days plants transferred to growth chamber for stress treatments. Plants maintained at $28^{\circ} \mathrm{C}$ and leaf samples collected 24 hours before heat 
stress (Control). Then plants exposed to high temperature at $40{ }^{\circ} \mathrm{C}$ (Heat Shock) and leaf samples collected after 24, 48 and 72 hrs of heat shock. After $72 \mathrm{~h}$ heat stress plants transferred to normal temperature $28^{\circ} \mathrm{C}$ (Recovery) and leaf samples collected after 24, 48 and $72 \mathrm{hrs}$. Fresh samples stored at $-80^{\circ} \mathrm{C}$ for biochemical and proteomic studies. After heat treatment following parameters were evaluated.

Fresh and Dry weight. 5 plants from each treatments (C, T1, T2, T3, R1, R2 and R3) were selected for fresh weight. These plants kept in oven at $37^{\circ} \mathrm{C}$ for one week for dry weight assesment.

Relative Membrane Permeability. Relative membrane permeability (RMP) was measured according to Yang et al. (1996). Fresh leaves excised from the plant, cut into small pieces and socked into falcon tubes containing disstilled water. After 30 minutes tubes were assayed for initial electrical conductivity (ECO). Then the tubes kept at $4^{\circ} \mathrm{C}$ for over night and then EC measured (EC1). EC2 was determined after autoclaved the tubes. This procedure were repeated three times for replication and RMP calculated according to the formula. RMP $(\%)=[(\mathrm{EC} 1-\mathrm{EC} 0) /(\mathrm{EC} 2-\mathrm{EC} 0)] \times 100$.

Determination of MDA content. MDA was calculated according to Heath and Packer (1968). Extracted leaf sample in 5\% TCA was centrifuged at $12000 \mathrm{rpm}$ for 10-15 minutes. Supernatant mixed with $1 \mathrm{ml} 0.5 \%$ TBA and warm at $95^{\circ} \mathrm{C}$. The samples then allowed to cool and centrifuged again at $7500 \mathrm{~g}$ and measured the absorbance first at $532 \mathrm{~nm}$ and then at $600 \mathrm{~nm}$.

Quantification of $\mathrm{H}_{2} \mathrm{O}_{2}$. Production of Hydrogen peroxide was assayed according to Jessup et al. (1994). $0.5 \mathrm{~g}$ fresh leaf sample homogenized in $5 \mathrm{ml} 0.1 \%$ TCA and centrifuged at $12000 \mathrm{rpm}$ for 15 minutes. $0.5 \mathrm{ml}$ Potasium phosphate buffer $(10 \mathrm{mM})$ and $1 \mathrm{ml}$ of $1 \mathrm{M}$ potassium iodide $(\mathrm{KI})$ mixed with the supernatant. Hydrogen peroxide absorbance was measured at $390 \mathrm{~nm}$ after vortex the mixture. software.

All data were subjected to analysis of variance (ANOVA) using SPSS v 17 statistical

\section{RESULTS OF RESEARCH}

Findings of the study about response of rice under heat stress in terms of germination potential and membrane thermostability are discussed below.

Promptness index (P.I) and germination percentage (G.P) of rice cultivars under high temperature $\left(42 \pm 3^{\circ} \mathrm{C}\right)$ stress for time intervals at germination stage showed inter-cultivar variations (Table 5). Promptness index, were significantly $(p \leq 0.05)$ different for all rice cultivars with increase in exposure of high temperature (Table 4). Data revealed that promptness index of "DR-82" (31.7) and "IR-8" (29.4) at T24 and "SADA HAYAT"(15.2) and "K-95" (13.0) at T48 were highest . While "K-95" (11.0) and "IR-8" (8.40) stood first in heat tolerance for germination speediness at T72 (Table 2). 'K-95', had the maximum heat tolerance index of promptness index at T24 and T72 followed by "DR-82" and "IR-8" at T24. High temperature stress reduced overall germination percentage and severity increased with increase in time duration (Table 3). Analysis of variance showed that germination percentage were significantly $(p \leq 0.05)$ reduced with increase in duration of heat stress. Similar to P.I. , G.S.I. were significantly different among cultivars (Table 4). At T24, "DR-82" (94.33\%) and "IR-8" (88.67\%) had highest germination percentage while "DR-83" $(62 \%)$ and "DR92" $(60 \%)$ showed lowest among other cultivars. Whereas, "SADA HAYAT" $(61 \%)$ and "K-95" (46\%) responded better while "IR-6" (13.30\%) and "SHAHKAR" (13.40\%) were poor at T48 and T72 respectively.

Relative membrane permeability (RMP) in terms of electrolyte leakge have shown in figure 2. At normal temperature $\left(28^{\circ} \mathrm{C}\right) \mathrm{EC}$ was not so much high and all varieties showed equal leakage While during heat shock membrane permeability was gradually increased many times as compare to control plants. At T24 cultivars "Sada Hayat" showed susceptibility with high RMP (66\%) while "IR-6" had lowest RMP (24\%) as compare to others. Exposure for $48 \mathrm{~h}$ exhibited again "Sada Hayat" as susceptible to heat stress with increased amount of electrolyte leakage (RMP 92\%) while "IR-8" as resistant with low RMP 
(38\%). Similarly heat stress for $72 \mathrm{~h}$ showed that duration of high temperature is also critical for cell membrane thermostability as evident from the increased electrolyte leakage than $48 \mathrm{~h}$ exposure. Here "Sada Hayat" again showed high RMP (98\%) as compare to others making its position in more susceptible group. During recovery condition plants showed gradually lowering RMP content which shows their regulatory function with changing environment. Cultivar "Sada Hayat" with RMP 97\% at T72 h showed low RMP 87\% at R24 h.

Table 2 - Promptness index of different rice cultivars exposed to high temperature stress for different time intervals at germination stage (Mean \pm standard error; $n=3$ )

\begin{tabular}{|c|c|c|c|c|}
\hline \multirow{2}{*}{ CULTIVARS } & \multicolumn{4}{|c|}{ High Temperature $\left(42^{\circ} \mathrm{C}\right)$ Stress during germination for } \\
\hline & $\mathrm{OHr}$ & $24 \mathrm{Hr}$ & $48 \mathrm{Hr}$ & $72 \mathrm{Hr}$ \\
\hline IR-6 & $36.9 \pm 1.04$ & $21.2 \pm 0.47$ & $2.80 \pm 0.40$ & $3.47 \pm 0.87$ \\
\hline IR-8 & $43.8 \pm 0.71$ & $29.4 \pm 0.66$ & $11.3 \pm 1.62$ & $8.40 \pm 1.06$ \\
\hline DR-82 & $42.7 \pm 0.83$ & $31.7 \pm 0.75$ & $8.00 \pm 0.52$ & $2.43 \pm 0.34$ \\
\hline DR-83 & $34.7 \pm 0.81$ & $20.6 \pm 1.99$ & $9.40 \pm 0.58$ & $6.60 \pm 0.17$ \\
\hline DR-92 & $38.2 \pm 0.47$ & $22.2 \pm 1.59$ & $10.0 \pm 0.58$ & $4.33 \pm 0.44$ \\
\hline K.95 & $36.5 \pm 0.48$ & $27.4 \pm 2.20$ & $13.0 \pm 1.15$ & $11.0 \pm 0.58$ \\
\hline SADA HYT & $36.1 \pm 0.26$ & $24.6 \pm 1.17$ & $15.2 \pm 1.15$ & $7.77 \pm 0.38$ \\
\hline SHAHKAR & $39.5 \pm 0.32$ & $23.8 \pm 1.15$ & $8.90 \pm 0.64$ & $2.10 \pm 0.17$ \\
\hline
\end{tabular}

Table 3 - Germination of different rice cultivars under high temperature stress at different time intervals (Mean \pm standard error; $n=3$ )

\begin{tabular}{|c|ccccc}
\hline CULTIVARS & \multicolumn{1}{c}{ High Temperature $\left(42{ }^{\circ}\right.$ C) Stress during germination for } \\
\hline IR-6 & $0 \mathrm{Hr}$ & $24 \mathrm{Hr}$ & $48 \mathrm{Hr}$ & $72 \mathrm{Hr}$ \\
IR-8 & $88.5 \pm 0.48$ & $66.37 \pm 2.23$ & $13.30 \pm 1.15$ & $16.50 \pm 0.58$ \\
DR-82 & $97.5 \pm 0.38$ & $88.67 \pm 2.20$ & $37.70 \pm 1.15$ & $28.27 \pm 0.64$ \\
DR-83 & $97.2 \pm 0.24$ & $94.33 \pm 0.62$ & $37.70 \pm 0.58$ & $15.40 \pm 0.06$ \\
DR-92 & $86.9 \pm 0.57$ & $62.70 \pm 0.76$ & $33.43 \pm 0.87$ & $33.33 \pm 0.09$ \\
K.95 & $92.1 \pm 0.67$ & $60.17 \pm 0.33$ & $40.07 \pm 0.58$ & $22.40 \pm 0.87$ \\
SADA HYT & $88.1 \pm 1.27$ & $75.70 \pm 2.48$ & $46.27 \pm 2.03$ & $46.60 \pm 0.58$ \\
SHAHKAR & $83.8 \pm 0.31$ & $60.87 \pm 2.41$ & $61.70 \pm 1.32$ & $40.07 \pm 0.58$ \\
\hline
\end{tabular}

Table 4 - Mean squares from analysis of variance (ANOVA) of data for germination $\%$ and promptness index $(\mathrm{PI})$ of rice seedling grown under varying temperature (Mean $\pm \mathrm{S}$.E.; $n=3$ )

\begin{tabular}{|c|c|c|c|}
\hline Main effects & & & \\
\hline Cultivars & 7 & $155.708^{* * *}$ & $23.766^{* * *}$ \\
\hline $\begin{array}{l}\text { Treatments } \\
\text { Interaction }\end{array}$ & 3 & $7041.801^{* * *}$ & $1759.243^{* * *}$ \\
\hline Lines $x$ Treatment & 21 & & \\
\hline Error & 81 & 132.040 & 9.329 \\
\hline
\end{tabular}

$* * *=$ significance at 0.05 level.

Membrane lipid per-oxidation (MDA) content were assessed and results have shown in figure number 2. Eight rice accessions exhibited different response in terms of MDA amount expressed in $\mathrm{nmol} / \mathrm{g} \mathrm{FW}$. At control condition all varieties showed MDA in the range of 0.2$0.3 \mathrm{nmol} / \mathrm{g} \mathrm{FW}$ while this ratio increased at stressed condition. Heat shock for $24 \mathrm{~h}$ (T24) showed "Shahkar" had lowest and "Sada Hayat" with highest amount of MDA among the group. Similarly at T48 again "Shahkar" and "Sada Hayat" ranked as tolerant and susceptible as compare to others. While at heat stress for $72 \mathrm{~h}$ manifested that "IR-6" had highest amount of MDA but cultivar "Shahkar" secured its position with lowest MDA content showing tolerance against heat stress. During back to normal condition cultivars exhibited improved cell membrane integrity. Here (R24) cultivars "DR-92" showed lowest MDA while "K-95" highest. At R48 the ranking remained same with gradually reduced amount of lipid peroxidation product. Significant increase in amount of TBARS concentrations under heat stress (Figure 3) exhibited that free radicals may be generated by 
heat shock which can start the peroxidation and destabilization of membrane lipids with subsequent membrane damage (Murakami et al., 2000).

Table 5 - Heat stress tolerance indices of different parameters of rice cultivars under high temperature $\left(42^{\circ} \mathrm{C}\right)$ for time intervals at germination stage

\begin{tabular}{|c|c|c|c|}
\hline CULTIVARS & TIME (Hrs) & P. & G.P \\
\hline \multirow{3}{*}{ IR-6 } & 24 & 0.574 & 0.663 \\
\hline & 48 & 0.075 & 0.133 \\
\hline & 72 & 0.094 & 0.165 \\
\hline \multirow[t]{3}{*}{ IR-8 } & 24 & 0.671 & 0.886 \\
\hline & 48 & 0.257 & 0.377 \\
\hline & 72 & 0.191 & 0.282 \\
\hline \multirow[t]{3}{*}{ DR-82 } & 24 & 0.742 & 0.943 \\
\hline & 48 & 0.187 & 0.377 \\
\hline & 72 & 0.056 & 0.154 \\
\hline \multirow[t]{3}{*}{ DR-83 } & 24 & 0.593 & 0.627 \\
\hline & 48 & 0.270 & 0.334 \\
\hline & 72 & 0.190 & 0.333 \\
\hline \multirow[t]{3}{*}{ DR-92 } & 24 & 0.581 & 0.601 \\
\hline & 48 & 0.261 & 0.400 \\
\hline & 72 & 0.113 & 0.224 \\
\hline \multirow[t]{3}{*}{ K.95 } & 24 & 0.751 & 0.757 \\
\hline & 48 & 0.356 & 0.462 \\
\hline & 72 & 0.301 & 0.446 \\
\hline \multirow[t]{3}{*}{ SDHT } & 24 & 0.681 & 0.608 \\
\hline & 48 & 0.421 & 0.617 \\
\hline & 72 & 0.215 & 0.400 \\
\hline \multirow[t]{3}{*}{ SHKR } & 24 & 0.602 & 0.711 \\
\hline & 48 & 0.225 & 0.462 \\
\hline & 72 & 0.053 & 0.134 \\
\hline
\end{tabular}

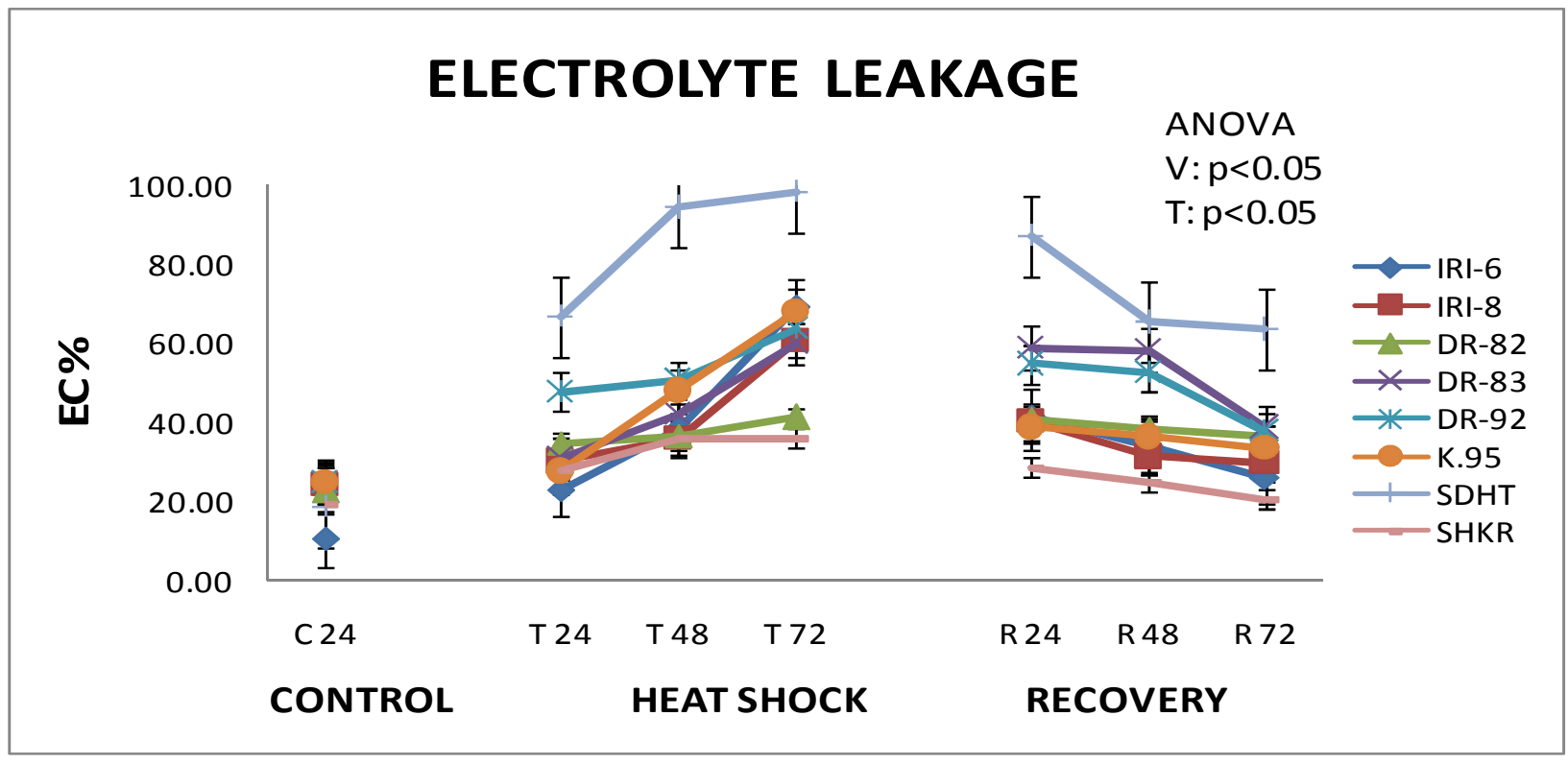

Figure 1 - Electrolyte leakage (EC\%) of 8 rice cultivars under control (C), heat shock (T24, T48, T72) and recovery (R24, R48, R72) treatments. ANOVA result shows that electrolyte leakage were significantly different among the vareities $(\mathrm{V})$ and at each treatments $(\mathrm{T})$ also.

Amount of free radicals $\left(\mathrm{H}_{2} \mathrm{O}_{2}\right)$ increased with oxidative stress $\left(42^{\circ} \mathrm{C}\right)$ as shown in figure number 3. At normal temperature (C) all accessions showed low content of $\mathrm{H}_{2} \mathrm{O}_{2}$ while at high temperature its concentration increased with duration of time. At heat shock for $24 \mathrm{~h}$ (T24) amount of hydrogen peroxide increased from average 5 micro mol per gram fresh weight to in the range of 10-20 $\mu \mathrm{M} / \mathrm{g} \mathrm{FW}$. "IR-8" showed lower content of $\mathrm{H}_{2} \mathrm{O}_{2}$ while cultivar "Sada Hayat" exhibited higher amount of $\mathrm{H}_{2} \mathrm{O}_{2}$ while "IR-8" had low at T24 among the rice 
varieties. Heat stress for $48 \mathrm{~h}$ (T48) time exposure uplift the free radicals content and created more oxidative stress condition to the plants. Here again "IR-8" showed lowest as T24 wile "DR-82" and "DR-83" showed increased amount of $\mathrm{H}_{2} \mathrm{O}_{2}$ than at T24. $72 \mathrm{~h}$ heat shock changed the senerio and it exhibited that "IR-6" had highest level of free radicals but with its consistency "IR-8" ranked as tolerant with lowest amount of hydrogen peroxide. During recovery treatments the group exhibited variation response towards production and accumulation of activated oxygen species.

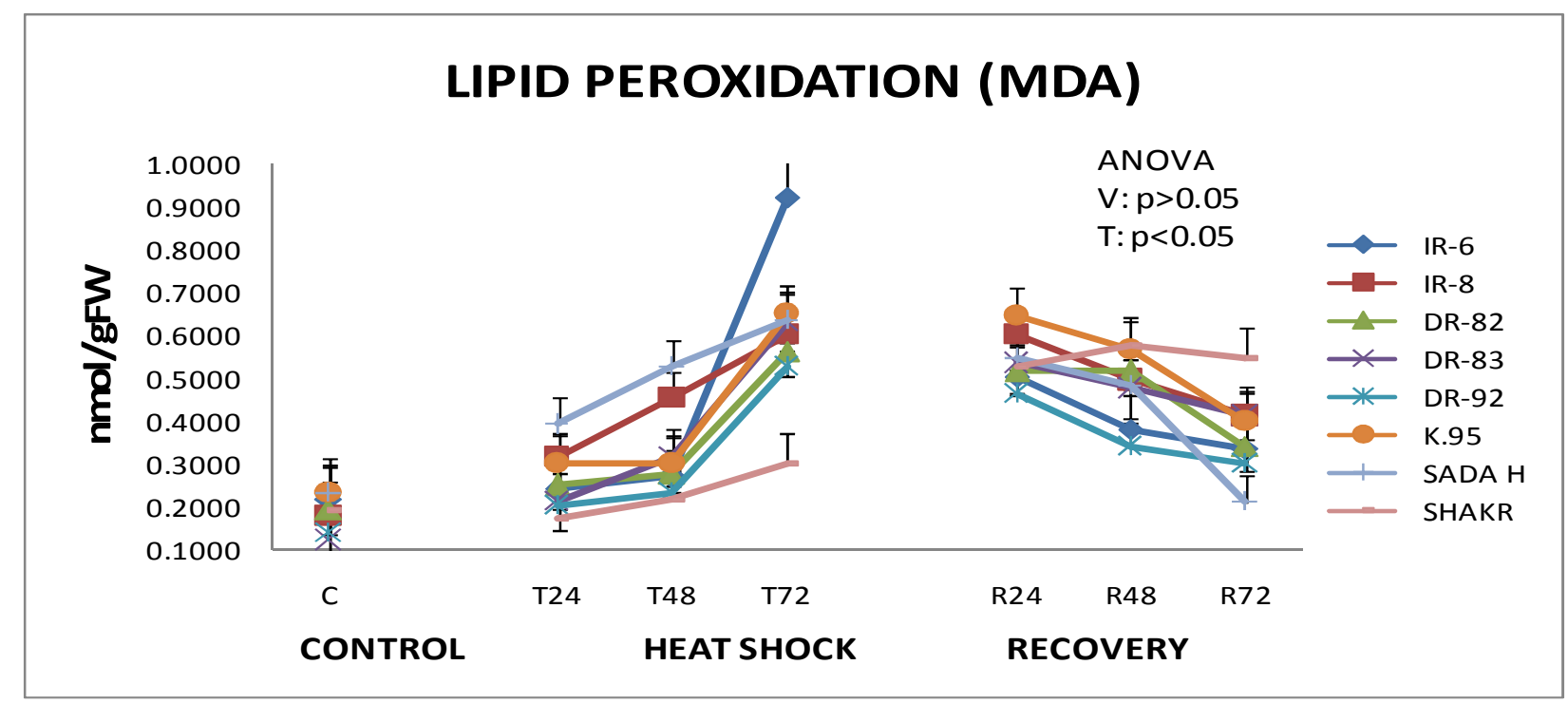

Figure 2 - MDA content of 8 rice cultivars under control (C), heat shock (T24, T48, T72) and recovery (R24, R48, R72) treatments. ANOVA result exhibited that MDA contant were not significantly different among the vareities $(V)$ and but MDA were significantly different at each treatments $(T)$.

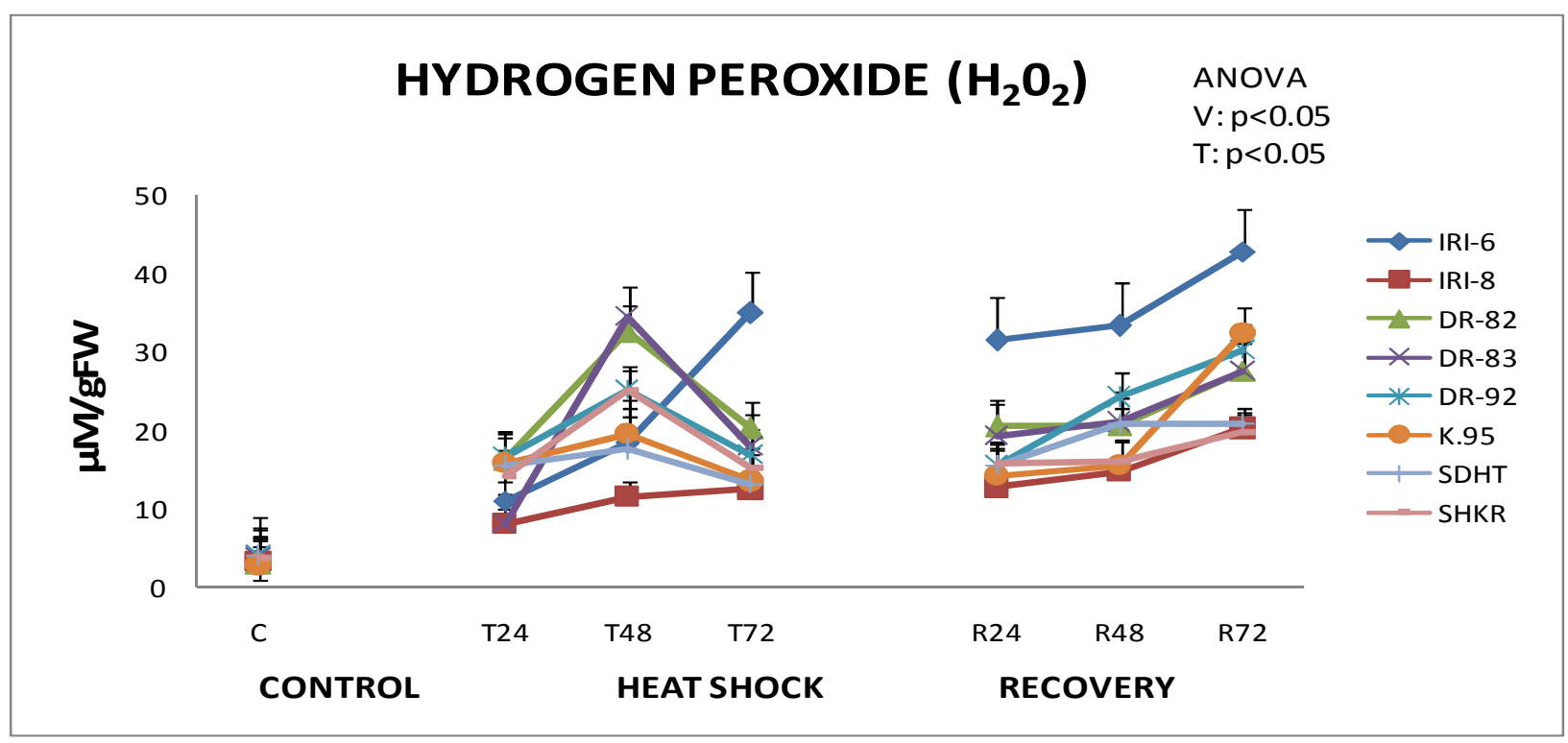

Figure 3 - Reactive hydrogen species $\left(\mathrm{H}_{2} \mathrm{O}_{2}\right)$ content of 8 rice cultivars under control $(\mathrm{C})$, heat shock (T24, T48, T72) and recovery (R24, R48, R72) treatments. ANOVA result exhibited that amount of free redicals $\left(\mathrm{H}_{2} \mathrm{O}_{2}\right)$ were significantly different among the vareities $(V)$ and treatments $(T)$ also.

The above results shows that high temperature is critical to cell membrane integrity and functions by increasing the amount of activated oxygen species, which deteriorate lipids and cause biological membrane more fluid and that exposure to heat stress for long periods of time may be lethal to the rice leaf. Similar outcomes also noticed in many pants including 
poplars. Taken together these findings suggested that cell membrane thermostability can be used as heat stress tolerance index.

\section{DISCUSSION}

It can be concluded from the outcomes of this investigation that germination is most important step in plant development and the temperature of environment should below $42{ }^{\circ} \mathrm{C}$ otherwise it may be delay or totally inhibit germination, depending on the cultivars. Secondly at seedling stage sustainability of crop mostly depends on cell membrane thermostability. Heat stress cause oxidative stress via generating free radicals, alteration of membrane protein structure. Deterioration of membrane lipids through autocatalytic peroxidation leads to decrease cell membrane integrity and becomes more fluide under stress as compare to non-stressed plants.

Yield loss depends upon the developmental stage at which the plant is exposed to any kind of unfavourable condition (Wahid et al. 2007). Therefore it is necessary to explore the inter-specific and intra-specific genetic variability for heat tolerance to cope with the stresses (Shah et al. 2011). While degree of stress tolerance of any crop can be exploited in absolute growth characteristics or relative terms in forms of tolerance indices. Among these, relative measure of stress tolerance is more reliable (Noreen et al. 2007; Ulfat et al. 2007) for screening for heat tolerance. El-Hendawy et al. (2005) proposed that screening for abiotic stress tolerance should be based on multiple parameters instead of single agronomic and physiological parameters for ranking of cultivars. Similarly, Ulfat et al. (2007) supported the ranking pattern for stress tolerance. The most important stage in establishment of seedling is germination stage which determines the sustainable crop production (Almansouri et al. 2001). The important point is to understand the response of plant towards any type of environmental stress at this stage, their sensitivity and survival (Mayer and Poljakoff-Mayber 1963). In the present study, eight rice cultivars were used to investigate the adverse effect of high temperature stress to the normal growth of plant, indicated as, speediness to germination, germination percentage, plant total height, shoot length, root length, fresh weight and dry weight, were much reduced as compared to control plants indicating that extreme temperature has negative influence on rice growth and yield. Our results clearly showed that high temperature adversely affected the germination process in all rice cultivars however inter-accessional variation in great magnitude was observed even among rice cultivars for germination and seedling establishment. High temperature stress significantly extended days, for germination which is evident from their speediness to germination (PI). At high temperature and with the increase in the duration of exposure to heat stress PI much lowered among all cultivars. It may be due the fact that heat stress reduces the water content of seeds, leading to the reduced activity of hydrolytic enzymes essential for carbohydrate metabolism and ultimately delayed germination (Wahid et al. 2007). Similarly seed germination decreased with increasing heat stress exposure from T24 to T72. The effect of heat stress on seed germination percentage were varied among the cultivars which clearly indicates that different cultivars respond different under stress condition. In conclusion, these heat tolerance indices such as, speed of germination and germination percentage etc. were found effective tool for early screening of heat tolerant and susceptible rice genotypes.

Certain abiotic stresses, including heat (Ferreira et al., 2006) or cold (Yan et al., 2006) are responsible to increase the cell membrane permeability, which is considered as an indication of membrane damage and deterioration. Cell membrane thermostability was determined through electrolyte leakage following treatment to physical stress factors, such as heat stress as has been used in soy been (Glycine max), sorghum (Sorghum bicolor) and melon (Cucumis melo). In the present study it is tried to explore effect of elevated temperature on the function and integrity of biological membrane. It is observed that electrolyte leakage increased many time with increase in duration of heat shock. When temperature increases kinetic movement of molecules accross the membrane increase, moving randomly and interecting with cell membrane. This will increase internal temperature 
of membrane proteins and consequently disturbes their structure. Protein degradation along with peroxidation of lipids due to free radicals cell membrane becomes more fluid under stress condition, which can easily assess through measurement of electrolyte leakge.

\section{REFERENCES}

[1] Akman, Z., 2009. Comparison of high temperature tolerance in maize, rice and sorghum seeds by plant growth regulators. J Animal and Vet Advan, 8, 358-361.

[2] Almansouri, M., Kinet, J. M. and Lutts, S. 2001. Effect of salt and osmotic stresses on germination in durum wheat (Triticum durum Dsf.). Plant Soil, 23, 243-254.

[3] Ashraf, M. 2004. Some important physiological selection criteria for salt tolerance in plants. Flora, 199, 361-376.

[4] Ashraf, M. Y., Akhtar, F., Hussain. and Iqbal, J. 2006. Screening of different accessions of three potential grass species from Cholistan desert for salt tolerance. Pak J Bot, 38, 130-133.

[5] Asharf, M. (2009). Biotechnological approach of improving salt tolerance using antioxidants as markers. Biotech. Adv. 27(1):84-93.

[6] Dias, P. M. B., Brunel-Muguet, S., Du'rr, C., Huguet, T. Demilly, D., Wagner, M. H. and Teulat-Merah, B. 2011. QTL analysis of seed germination and pre-emergence growth at extreme temperature in Medicago truncatula. Theor Appl Genet, 122, 429-444.

[7] Eckardt, N. A. 2009 . Sequencing the rice genome. The Plant Cell, 12, 2000-2017.

[8] El-Hendawy, S.E. Hu, Y. Yakout, G.M. Awad, A.M. Hafiz, S.E. and Schmidhalter, U., 2005. Evaluating salt tolerance of wheat genotypes using multiple parameters. Eur $\mathrm{J}$ Agron, 22, 243-253.

[9] Eldakak, E., Milad, S.I.M, Nawar, A.I. and Rohila, J. S. (2013). Proteomics: abiotechnology tool for crop improvement. Front. In Plant Science. 4:1-12.

[10] Grass, L. and Burris, J.S., 1995. Effect of heat stress during seeds development and maturation on wheat (Triticum durum) seed quality 1 Seed germination and seedling vigors. Can J Plant Sci, 75, 821-829.

[11] IPCC, 2001. In: Houghton, T.J. Ding, Y. Griggs, D.J. Noguer, M. Van der Linden, P.J. Da, X. Maskell, K. and Johnson, C.A. (eds). Climate change 2001: Scientic Basis. Cambridge University Press, New York, USA.

[12] Mayer, A.M. and Poljakoff-Maber, A., 1998. The germination of seeds. Oxford, London: Pergamon Press.

[13] McDonald, M.B., 2000. Seed Priming. In: Black, M. Bewley, J.D. (eds). Seeds Technology and Its Biological Basis. Sheffield Academic Press Ltd Sheffield, UK. pp 287-325

[14] Muhammad, A.R. and Tarpley., 2009 . Impact of High Night time Temperature on Respiration, Membrane Stability, Antioxidant Capacity, and Yield of Rice Plants. Crop Sci, 49, 313-322.

[15] Noctor, G. and Foyer, C.H. (1998). Ascorbate and glutathione: Keeping active oxygen under control. Annu. Rev. Plant Physiol. Plant Mol. Biol. 49:249-297.

[16] Noreen, Z. Muhammad, A. and Mahmood, U.H. 2007. Inter accessional variations for salt tolerance in pear (Pisum Sativum L.) at germination and screening stage. Pak $\mathrm{J}$ Bot , 39(6), 2075-2085.

[17] Nokagawa, H. Horie, T. and Matsui, T., 2003. Effects of climate change on rice production and adoptive technologies. In: Rice Science: Innovations and Impact for livelihood. Proceedings of the international Rice Reaserch Conference Beijing China 16-19 September, 2002, 635-658.

[18] Peng, S. Huang, J. Sheehy, J.E. Laza, R.C. Visperas, R.M. Zhong, X. Centeno, G.S. Khush, G.S. and Cassman, K.G., 2004 .Rice yields decline with higher night temperature from global warming. Proc Natl Acad Sci USA, 101(27), 9971-9975.

[19] Prasad, P.V.V. Boote, K.J. Allen, L.H. Sheehy, J.E. and Thomas, J.M.G., 2006. Species, ecotype and cultivar differences in spikelet fertility and harvest index of rice in response to high temperature stress. Field Crops Res, 95, 398-411. 
[20] Sass, R.L. and Cicerone, R.J., 2002. Photosynthate allocations in rice plants: Food production or atmospheric methane?, Proc Natl Acad Sci USA, 99, 11993-11995.

[21] Shah, F. Huang, J. Cui, K. Nie, L. Shah, T. Chen, C. and Wang, K., 2011. Impact of high-temperature on rice plants and its trait related to tolerance. J Agri Sci Cambridge, 149 (5), 545-549.

[22] Southworth, Jane. J. Randolph, M. Harbeck, O. Doering, R. Pfeifer, D. Rao, J. and Johnston., 2000. Consequences of future climate change and changing climate variability on maize yields in the Midwestern United States. Agriculture, Ecosystems, and the Environment, 82, 139-158.

[23] Spierty, J.H.R. Hamer, R.J. Xu, H. Primo-Martin, C. Don, C. and Van der Putten, P.E., 2006. Heat stress in wheat (Triticum aestivum L.): effect on grain growth and quality traits. European Journal of Agronomy, 25, 89-95.

[24] Takeda, K. Zhao, I. Zhong, J. Liu, U. and Mano, Y., 1995. Selection test of barley and wheat varieties in the Heilonggang region of China. Proceedings of China-Japan joint Symposium, Impact of salanization and acidification on terrestrial ecosystems and their rehabilitation in East Asia. Beijing China Nov, 3-5, pp 87-90.

[25] Ulfat, M. Athar, H.R. Ashraf, M. Akram, N.A. and Jamil, A., 2007. Appraisal of Physiological and biochemical selection criteria for evaluation of salt tolerance in canola (Brassica napus L.). Pak J Bot, 39(5), 1593-1608.

[26] Vaderauwers, S. De Block, M. Van De Steene, N. Van De Cotte, B. Metzlaff, M. and Breusegem, F.V., 2007. Silencing of poly (ADP-ribose) polymerase in plants alters abiotic stress signal transduction. Proc Natl Acad Sci USA, 104(38), 15150-15155.

[27] Wahid, A. Gelani, S. Ashraf, M. and Foolad, M.R., 2007. Heat Tolerance in Plants: An Overview. Environ Exp Bot, 61, 199-223.

[28] Wahid, A. and Close, T.J., 2007. Expression of dehydrins under heat stress and their relationship with water relations of sugarcane leaves. Biol Plant 51, 104-109.

[29] Wassmann, R. Jagadish, S.V.K. Sumfleth, K. Pathak, H. Howell, G. Ismail, A. Serraj, R. Redona, E. Singh, R.K. and Heuer, S., 2009a. Regional vulnerability of climate change impacts on Asian rice production and scope for adaptation. Advance in Agronomy, 102, 91-133.

[30] Yoshida, S. Satake, and T. Mackill, D.S. 1981. High temperature stress in Rice. IRRI Research Paper Series 67. Los Banos, The Philippines: IRRI.

[31] Xu, S., Li, J., Zhang, X., Wei, H. and Cui, L. (2006). Effect of heat acclimation pretreatment on changes of membrane lipid peroxidation, antioxidant metabolites, and ultrastructure of chloroplast in two cool-season turfgrass species under heat stress. Environ. Exp. Bot. 56:274-285. 